\title{
Comparison of Time Taken for Feeding Stable Preterm Babies Between Regular Nurse Feeding and Feeding with Feed Rail-A Randomized, Controlled Study
}

\author{
Deepti Thandaveshwara ${ }^{1} \cdot$ Sushma Krishnegowda ${ }^{1} \cdot$ Aditya Batra $^{1} \cdot$ Srinivasa Murthy Doreswamy ${ }^{1}$ (I)
}

Received: 23 October 2020 / Accepted: 12 April 2021 / Published online: 31 May 2021

(C) Dr. K C Chaudhuri Foundation 2021

\begin{abstract}
Objective To compare the variation of feeding rate and time taken for feeds between manual and automated feeding via feed rail. Methods Stable preterm babies weighing between 1 and $2 \mathrm{~kg}$, on partial or full enteral feeds via gavage were randomized into gravity and feed rail feeding group, respectively. Ten nurses and 4 babies were paired to form 40 nurse-baby pairs for the study. Forty feeding events in each groups were recorded.

Results The median duration of feeding in the feed rail group was $18.5 \mathrm{~min}$ compared to $15 \mathrm{~min}$ in nurse-led feeding $(p=0.34)$. Feeding rate corrected for bodyweight ranged between 0.8 and $2.3 \mathrm{~mL} / \mathrm{kg} / \mathrm{min}$ in the feed rail group compared to 2.5 and $8.9 \mathrm{~mL} /$ $\mathrm{kg} / \mathrm{min}$ in the control (manual gravity feed) group. This difference in the feed rate variation was statistically significant ( $p$ value of $<0.0001$ ). The median feed rate with feedrail was $1.3 \mathrm{~mL} / \mathrm{min}$ as compared to $4.1 \mathrm{~mL} / \mathrm{min}$ with manual gravity feeds. During the feed rail feeding, nurses were hands-free for $80 \%$ of the time.

Conclusion Feed rail feeding results in slow, sustained, and minimal variation in gravity feeding at a rate of 1 to $2 \mathrm{~mL} / \mathrm{kg} / \mathrm{min}$ without affecting the feeding duration compared to manual nurse-led feeding.

Trial Registered Clinical Trials Registry India (CTRI/2020/06/025958).
\end{abstract}

Keywords Feed rail $\cdot$ Gravity feeding $\cdot$ Automated feeding $\cdot$ Preterm $\cdot$ Neonates

\section{Introduction}

Survival and outcome of preterm and low-birth-weight babies are heavily dependent on successful enteral feeding. Feeding challenges in these babies are diversity in their feeding abilities and their fluid and nutritional requirements, compared to normal-birth-weight infants [1].

Successful breast-feeding requires effective sucking, swallowing, and proper coordination between suck/swallow and breathing in the babies, all of which mature with increasing gestation. Until then, gravity feeding via a gavage tube is a common mode in low-birth-weight and preterm babies less than 32 wk of gestation [2]. Babies can be fed via nasogastric

Srinivasa Murthy Doreswamy

drdsrinivasa@gmail.com

Deepti Thandaveshwara

deeptiadarsh@gmail.com

1 Department of Pediatrics, JSS Medical College, JSS Academy of Higher Education and Research, 70, PRAKRUTHI, BEML 2nd Stage, Rajarajeshwari Nagara, Mysuru, Karnataka 570022, India tube (NG) either intermittently, typically over 10 to $20 \mathrm{~min}$ every 2 or $3 \mathrm{~h}$ (bolus feed), or continuously, using an infusion pump [3]. Neonatologists recourse to pump feeds only when the baby does not tolerate bolus feeds. The important difference is that the gavage feeding is assisted by gravity and given in pulses, and hence, mimics breast-feeding at the gastric end, whereas pump-feed is positive pressure (forced) feed. Using either technique, a slow and steady rate of feeds is desirable to avoid complications.

Although the authors could not find any scientific literature prescribing appropriate rate of gravity feeding, a full feed is recommended to be given over 10 to $15 \mathrm{~min}$ depending on the tolerance of the baby. This is roughly equivalent to 1 to $2 \mathrm{~mL} / \mathrm{kg} / \mathrm{min}$ [2].

Slow bolus feeds are preferred in most cases against continuous feeds [4]. Voluminous and rapid feeding is shown to be harmful to the baby [5]. The feeding practices vary in different neonatal units across the world, which is expected due to the involvement of human factors like nursing skill and resource issues like nurse:baby ratio. Gravity feeding rates can show significant variation due to these factors. An earlier study by the authors has shown that it is indeed true [6]. 
As a solution to minimize this wide variation in feeding rate, the authors hypothesized that the feeding process could be automated to a certain extent, thereby reducing the variation in feeding rate, maintaining uniformity, and also to lessen the burden on the nursing staff in lowresource units. The authors developed an automated gravity feeding device-'feed rail', to achieve a slow, sustained gravity feeding with minimal variation in the feeding rate by nurses. Due to automation, this device is also expected to give hands-free time for nurses. This study was conducted to compare the variation of feeding rate and time taken between nurse-led and 'feed rail' gravity feeding in stable preterm neonates and also to calculate the hands-free time during automated feed rail feeding.

\section{Material and Methods}

This was a hospital-based, randomized, controlled study conducted during June and July 2020 in the neonatal unit of JSS Medical College Hospital, Mysuru, Karnataka, India. Feed rail (Fig. 1) is a mechanical device with electronic controls that lifts the syringe filled with milk. The present model does not have speed control. The syringe is fitted to the syringe holder and the operation is started. The syringe is lifted with the help of a motor and lead screw. The lifting is slow and intermittent with a pause in between the lifts to facilitate the gravity run of milk from the syringe to the baby. The device in itself does not exert any positive pressure to facilitate the flow of milk. As the syringe is lifted slowly, the milk is delivered into the stomach via gavage at a slow, consistent rate with intermittent small volume bolus. The operation can be paused at any level, if the operator finds the milk flow rate is more than desired. A rewind button ensures lowering the syringe barrel and pauses it at a height where the caregiver feels appropriate. This is designed to allow the nursing cues to guide the feeding which is very crucial for successful feeding. After completing feeding, the syringe is lowered with the help of the rewind button, removed from the housing. A safety sensor (Supplementary Fig. 1) attached to the cheek of the baby and tied to the gavage tube with the help of medical adhesive tape ensures that the accidental dislodgement of the gavage tube is indicated with the help of a beep sound. Consequently, the ascent of the syringe is arrested pending the attention of the caregiver. (Patent pending: Indian patent office application no 201741010900).

Fig. 1 Feed rail

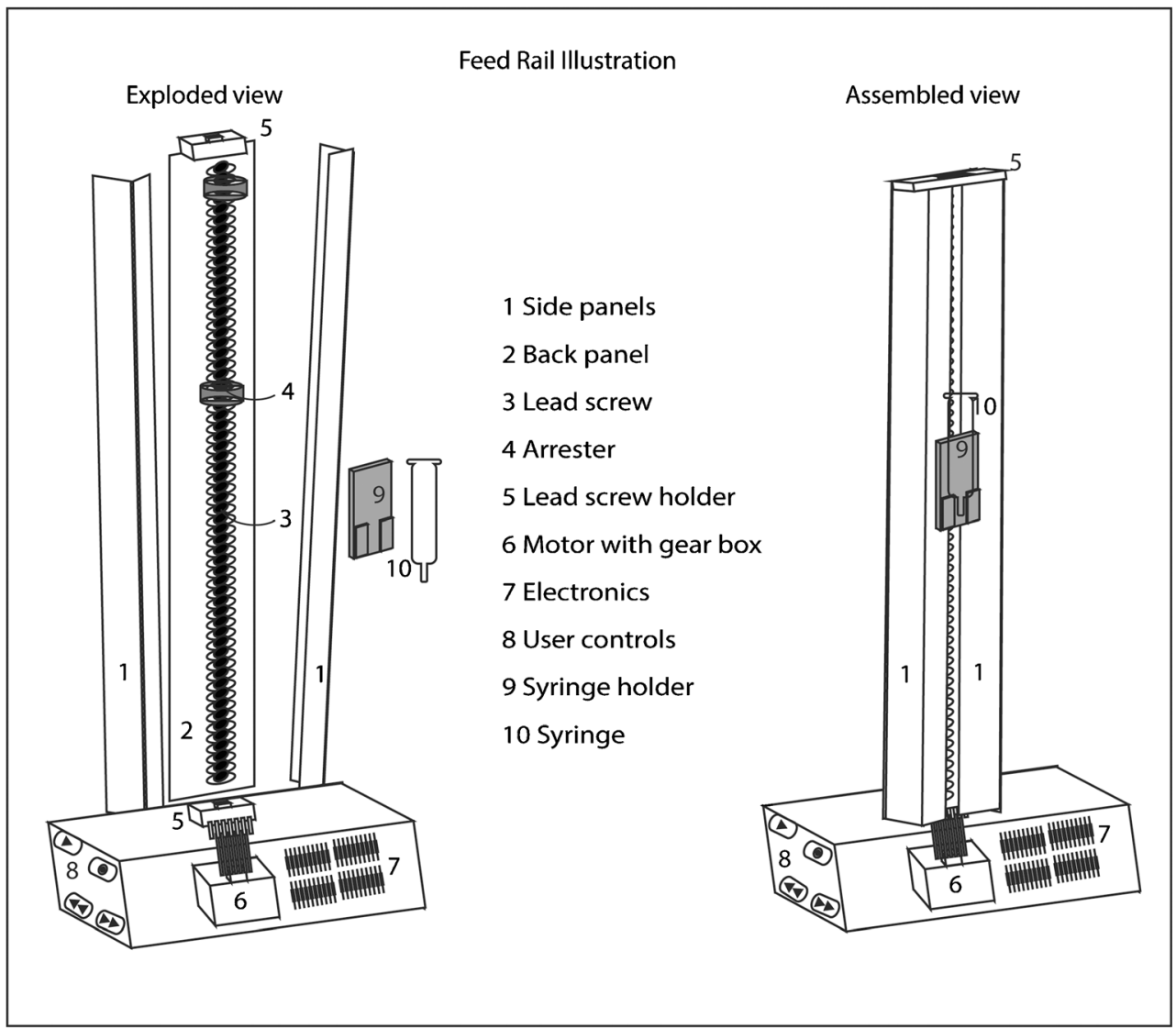


Babies weighing less than $2 \mathrm{~kg}$, tolerating oral feeds, and with at least $50 \%$ of their nutritional requirement through gavage were included in the study. Sick babies on a ventilator and inotropes were excluded. A unique pair of nurse and baby constituted the study unit (study subject). Forty such study units were included in the study.

A NG of size 6 Fr was inserted and fixed at the desired length. Determination of acidic status of the gastric aspirate using a $\mathrm{pH}$ paper confirmed the position of the tube. To confirm that the tube had not migrated, the level of graduation at which the tube was secured to the face was noted and checked each time before initiating the feed. Randomization of the order of feeding was done (manual and feed rail group). The nurse in charge administered the first feed as per the randomization. Later the same study unit was crossed over to another method of feeding.

In the intervention group, the feed rail was set up near the baby who needed to be fed. The empty syringe barrel was fastened to the NG tube. The safety sensor (Supplementary Fig. 1) was taped to the tube as well. The required volume of feeds was filled into the syringe barrel and strapped to the designated slot in the feed rail. The machine was switched on to run. The nurse observed the rate of flow and paused the machine when she was convinced that the flow rate was appropriate for the baby. The time taken from switching on the feed rail to completion of desired volume of feed was recorded.

In the control group, the prescribed volume of feeds was administered by the assigned nurse with the standard gravity feeding technique. The height of the syringe was paused at the level the nurse decided to be optimal for milk flow rate. Babies were burped following each feed. The assigned nurse filled in the nursing observation sheet regarding the vitals, onset, and conclusion of feeding and the amount of milk spilled in each group. Data of the same, along with other demographic data, were collected by one of the investigators.

The authors conducted a pilot study and noted that the standard deviation of the difference between the two groups was $6.6 \mathrm{~min}$ [6]. Assuming the standard deviation of true difference to be at least $5 \mathrm{~min}$ between the two groups with an alpha error of 5\% and a beta error of $10 \%$, the authors needed 38 subjects in each control and intervention group. This was rounded off to 40 subjects (nurse-baby pair). Each nurse-baby pair executed a set of feeding, one with control technique and the other with intervention technique.

As this was a new device that is not an implant, the institutional ethics committee after going through the regulatory requirements, approved this device for use in the research scenario. The institutional ethics committee approved the study. Informed consent was taken from parents. The trial was registered under the Clinical Trials Registry of India (CTRI/2020/06/025958).

\section{Results}

A total of 40 nurse-baby pairs were included in this study. Ten nurses and 4 babies were combined to obtain 40 nurse-baby pairs. The gestational age of the subjects ranged between 28 and $32 \mathrm{wk}$ with weight ranging from $980 \mathrm{~g}$ to $1600 \mathrm{~g}$. The included neonates aged between 10 and $44 \mathrm{~d}$ of life (corrected gestational age between 33 to $35 \mathrm{wk}$ ). The median gestational age [interquartile range (IQR)] at the time of inclusion was 34 wk (34-34). The median (IQR) weight of the babies at the time of inclusion was $1050 \mathrm{~g}$ (980-1357).

Six groups got randomized to be initially fed by manual gravity feeding. The rest were randomized to feed rail feeding (Fig. 2). The mean (SD) volume of feed in the feed rail group was $16.3(0.88)$ and in the manual group was $16.5(0.9) \mathrm{mL}$. Seven $(17.5 \%)$ babies were on partial enteral feeds and the rest were on full enteral feeds. Out of 7 on partial feeds, 3 were randomized to manual gravity feeds and 4 to feed rail feeds.

The median feed duration for a group of 4 neonates was $18.5 \mathrm{~min}$ (95\% CI 14.2-19.2) in the feed rail group and $15.1 \mathrm{~min}$ (95\% CI 14.3-16.6) in the manual gravity feeding group. However, it was not statistically significant (Fig. 3).

The median (IQR) [Range] flow rate executed with feed rail was $1.3(1-1.9)[0.9-2.3] \mathrm{mL} / \mathrm{min}$ and in the gravity feeds was $4.1(3.7-5)[3.2-8.5] \mathrm{mL} / \mathrm{min}$. The rate of feeding corrected for body weight $(\mathrm{mL} / \mathrm{kg} / \mathrm{min})$ showed a significant difference between the feed rail and manual gravity feeding group (Fig. 3). The feeding rate in the feed rail group ranged from a minimum of $0.8 \mathrm{~mL} / \mathrm{kg} / \mathrm{min}$ to a maximum of $2.3 \mathrm{~mL} /$ $\mathrm{kg} / \mathrm{min}$, whereas in the nurse-led feeding group, it was between $2.5 \mathrm{~mL} / \mathrm{kg} / \mathrm{min}$ and $8.9 \mathrm{~mL} / \mathrm{kg} / \mathrm{min}$. The median rate was 1.3 and $4.1 \mathrm{~mL} / \mathrm{kg} / \mathrm{min}$ in the feed rail and manual gravity feed group, respectively. The median difference between the two groups was $2.8 \mathrm{~mL} / \mathrm{kg} / \mathrm{min}$ (CI 2.2-2.9) and this was statistically significant ( $p$ value $<0.0001$ ).

Variation in the feeding rate was $1.5 \mathrm{~mL} / \mathrm{kg} / \mathrm{min}$ in the feed rail group compared to $6.4 \mathrm{~mL} / \mathrm{kg} / \mathrm{min}$ in the manual gravity feeding group. The variation in feeding rate when manually fed was 4.2 times higher than when fed by the feed rail.

Hands-free time was estimated for the feed rail group. As the nurse executing the feed rail feeds was nearly $100 \%$ hands-free after the commencement of feeds (except for pressing the pause button), the authors included preparation time in both groups to calculate hands-free time. Preparation for feed rail feed ranged from 30 to $60 \mathrm{~s}$ and that for manual feeds ranged from 60 to $90 \mathrm{~s}$. Hence, $60 \mathrm{~s}$ were added for each feed to calculate the total feed time. Mean (SD) total feed time per baby for the feed rail group was $5.3(0.74) \mathrm{min}$, whereas in the manual gravity feeding group it was $5(0.74)$.

Mean (SD) hands-free time in the feed rail group was 4.3 (0.7) $\mathrm{min}$. In the feed rail group, the nurses were free for $80 \%$ of the total feed time, whereas no such hands-free time was available for the nurse indulged in manual gravity feeding. 
Fig. 2 Consort diagram

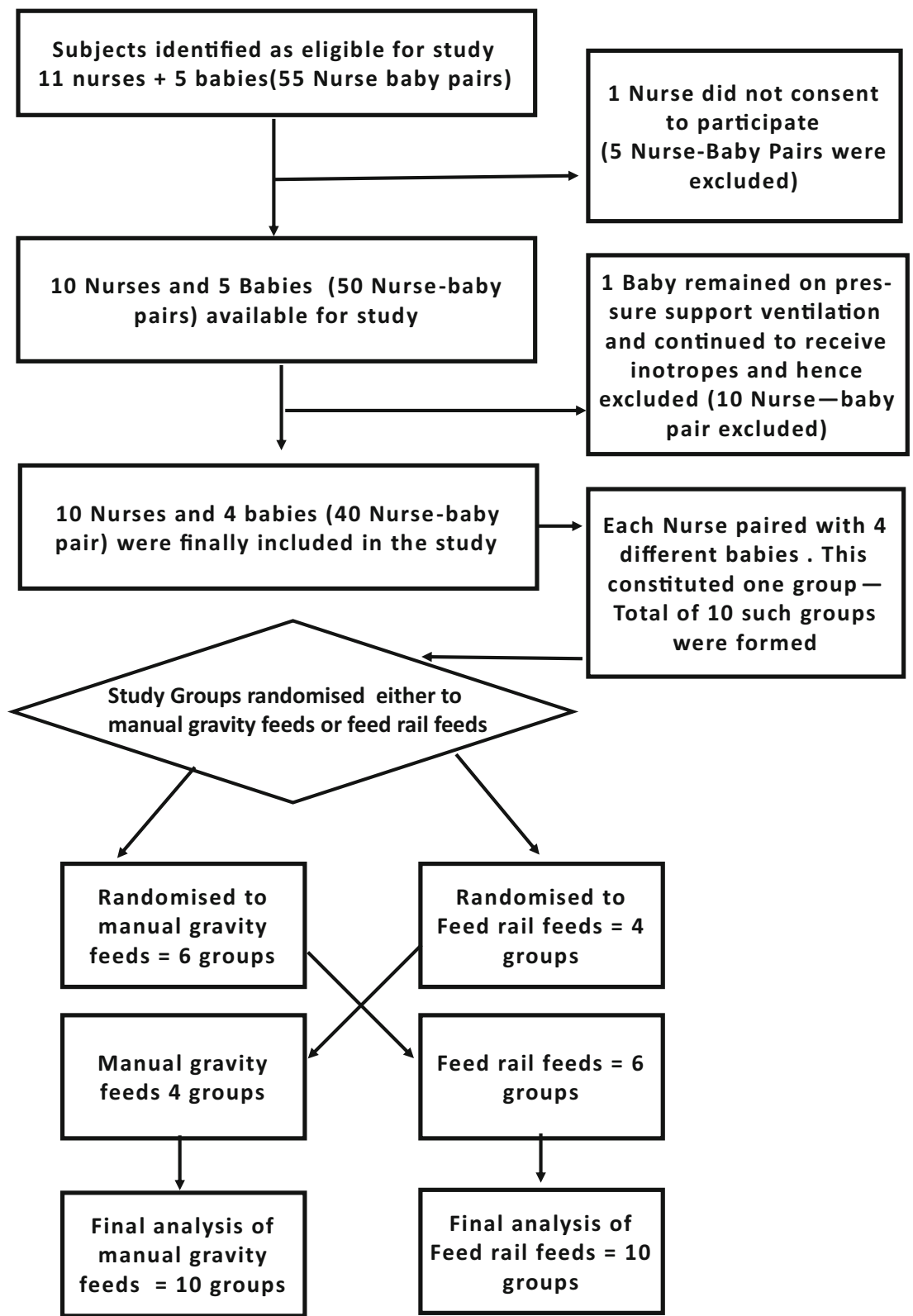

There were no issues during feeding in both groups. Although one baby vomited in the feed rail group and three in the manual gravity group within half an hour of completion of feeding, the difference was not statistically significant.

\section{Discussion}

Larger bolus feeds may cause a temporary impairment in respiratory functions, especially in infants with respiratory distress syndrome. Rapid feeding might lead to abdominal distension, discomfort, and reflux, whereas slow feeding might lead to indigestion due to short intervals between feed [5].
According to a recent international survey, feeding practices showed marked variations in neonatal intensive care units in different countries [7]. However, most of these studies have investigated various methods of gravity feeding. Unfortunately, no literature looking at the feeding rates with respect to various personal attributes of the health care provider could be found. The authors attempted to address this issue in one of their earlier studies in which they demonstrated a variation of 32 times between different nurses and 17 times with the same nurse feeding at different times, with respect to the rate of gravity feeding [6]. In this study, it was noted that the variation of the feeding rate among nurses, was dependent on individual skills, dynamics of nurse-baby pair, and whether it was day or night. 
Fig. 3 Comparison of total duration of feeds (for a group of 4 babies) and feeding rate per $\mathrm{kg}$ bodyweight between feed rail feeding and manual gravity feeding

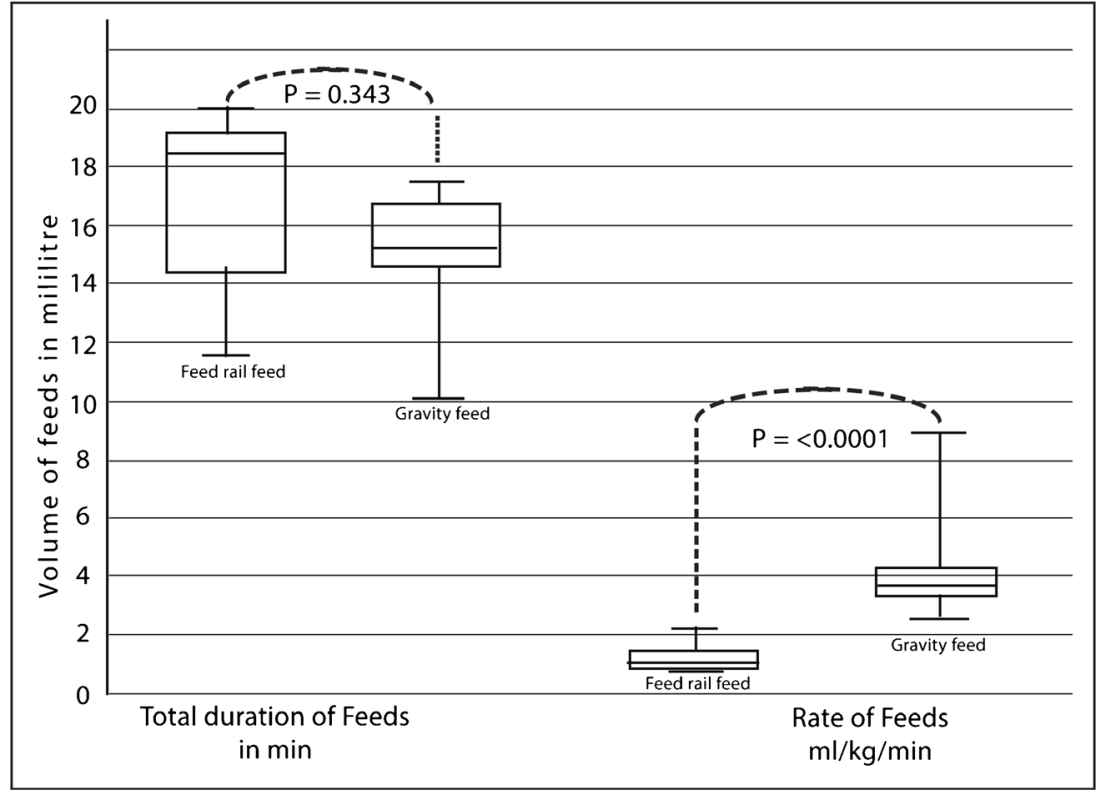

All these factors can be controlled if the process is automated resulting in a slower, sustained and uniform rate of gravity feeding. Feeding the babies with the use of this automated device, the authors have demonstrated that human factors can be minimized to a great extent and reduce the variation in the rate of gravity feeding. This is achieved without affecting the time duration needed to feed. All this is achieved even while the caring nurse can exercise her discretion on the optimal flow rate based on her experience with that baby. In other words, the human factor necessary for nursing neonates (nursing cues) is still kept intact while automation significantly reduces the undesirable variation in the feed rate.

On top of it, nurses were hands-free for most of the duration of feeds, which translated to better utilization of time for clinical observation and documentation. The authors also found increased nursing satisfaction due to better nursing care on two points. One was that they could observe the babies and complete documentation during the actual feeding event and second, multiple babies could be fed simultaneously eliminating the distress of seeing unfed babies crying of hunger as one baby was fed. The hands-free time during the feeding up to the tune of $80 \%$ meant greatly reduced physical workload on the nurses, which could improve the quality of nursing care. Few more similar studies at different levels of neonatal care are needed to establish the safety of this device for a general recommendation.

The limitation of the study was that the sample size was small to assess the adverse events associated with the new intervention. A large sample size may help in addressing this issue.

\section{Conclusion}

Significant inter and intrapersonal variability in feeding rate during gravity feeding of neonates exists. But automated feeding using the 'feed rail' can lead to a sustained and uniform feeding at a rate of $1-2 \mathrm{~mL} / \mathrm{kg} / \mathrm{min}$.

Multiple babies can be fed simultaneously by a single nurse. Sufficient hands-free time is available for nurses for clinical observation and documentation during the feeds.

Supplementary Information The online version contains supplementary material available at https://doi.org/10.1007/s12098-021-03770-0.

Author's Contribution DT helped in the randomization and preparation of the manuscript; SK helped in the study design; SMD developed the feeding device and did the statistical analysis; $\mathrm{AB}$ supervised the feeding procedure and collected the data. SMD will act as guarantor for this paper.

\section{Declarations}

Ethical Committee Approved by the Institutional Ethics Committee, JSS Medical College (JSS/MC/IEC/200418/04 NCT/2018-19) on 20.4.2018.

Conflict of Interest None.

Source of Funding JSS Academy of Higher Education and Research, Mysuru, Karnataka, India funded for the development of the feed rail equipment. 


\section{References}

1. Dutta S, Singh B, Chessell L, et al. Guidelines for feeding very low birth weight infants. Nutrients. 2015;7:423-42.

2. Jeeva Sankar M, Agarwal R, Mishra S, Deorari AK, Paul VK. Feeding of low birth weight infants. Indian J Pediatr. 2008;75:45969.

3. Premji SS, Chessell L. Continuous nasogastric milk feeding versus intermittent bolus milk feeding for premature infants less than 1500 grams. Cochrane Database Syst Rev. 2011;11:CD001819.

4. Hay WW Jr. Strategies for feeding the preterm infant. Neonatology. 2008;94:245-54.

5. DeMauro SB, Gray MM. Feeding intervals in very low birth-weight infants in intensive or critical care. In: Rajendram R, Preedy VR,
Patel VB, editors. Diet and nutrition in critical care [internet]. New York, NY: springer; 2015. p. 779-94. Available at: https://doi.org/ 10.1007/978-1-4614-7836-2_52. Accessed 9 Aug 2020.

6. Krishnegowda S, Vasudev PH, Doreswamy SM, Veena S, Hemavathi M. A study of variation in the tube feeding rate by nurses in a tertiary NICU. J Nepal Paediatr Soc. 2017;36:222-6.

7. Klingenberg C, Embleton ND, Jacobs SE, O'Connell LAF, Kuschel CA. Enteral feeding practices in very preterm infants: an international survey. Arch Dis Child Fetal Neonatal Ed. 2012;97:F56-61.

Publisher's Note Springer Nature remains neutral with regard to jurisdictional claims in published maps and institutional affiliations. 